\title{
Erratum to: Diversity of Endosymbiotic Nostoc in Gunnera magellanica from Tierra del Fuego, Chile
}

\author{
M. A. Fernández-Martínez • A. de los Ríos • \\ L. G. Sancho • S. Pérez-Ortega
}

Published online: 1 June 2013

(C) Springer Science+Business Media New York 2013

\section{Erratum to: Microb Ecol}

DOI 10.1007/s00248-013-0223-2

The title of this article has been revised to "Diversity of Endosymbiotic Nostoc in Gunnera magellanica from Tierra del Fuego, Chile."

'Haplotype sequences have been deposited in Gen Bank database. Accession numbers are KF142667-KF142678 for 16S-ITS sequences and KF142679-KF142710 for rbcLX sequences'.

The online version of the original article can be found at http:/ dx.doi.org/10.1007/s00248-013-0223-2.

M. A. Fernández-Martínez $(\varangle) \cdot A$. de los Ríos $\cdot S$. Pérez-Ortega Museo Nacional de Ciencias Naturales-CSIC, C/Serrano 115 bis., 28006 Madrid, Spain

e-mail: ma.fernandez@mncn.csic.es

A. de los Ríos

e-mail: arios@ccma.csic.es

S. Pérez-Ortega

e-mail: sperezortega@ccma.csic.es

L. G. Sancho

Departamento de Biología Vegetal II, Facultad de Farmacia, Universidad Complutense de Madrid, 28040 Madrid, Spain

e-mail: sancholg@farm.ucm.es 